\title{
Novas Estratégias Produtivas na Amazônia: estudo sobre os produtores agropecuários familiares no Sudoeste Paraense
}

\author{
José Antonio Herrera ${ }^{1}$, Pedro Ramos² e João Ulisses Barata da Silva ${ }^{3}$
}

Resumo: A Amazônia é integrada à economia nacional de modo que o capital se aproveita das assimetrias das trocas não leais e desiguais. A exploração dos recursos passa ser mais intensa, degradando o meio ambiente e agravando os problemas sociais. A imposição do capital nas relações estabelecidas, apesar de transformar a produção agropecuária familiar, não a eliminou, e essa apresenta distintas formas de produção e diferentes relações sociais. Partindo dessa premissa, buscou-se compreender as estratégias de produção que constituem a produção agropecuária familiar no Sudoeste Paraense. O estudo foi realizado em três municípios: Pacajá, área de Colonização Antiga; Anapu, área de PDS (Projeto de Desenvolvimento Sustentável); e Senador José Porfírio, a área de Projeto de Assentamento Convencional do Incra (Instituto Nacional de Colonização e Reforma Agrária). Foram acompanhadas cento e cinquenta (150) famílias durante o ciclo agropecuário 2007-2008. Como procedimentos metodológicos, foram utilizados parâmetros qualitativos (observação in loco) e quantitativos (análise estatística), podendo elucidar um mosaico (trajetórias, perspectivas e tendências) que compõem a unidade de diversidade da produção agropecuária familiar que resulta das distintas bases materiais que as famílias dispõem para estabelecerem seus projetos a médio e longo prazo.

Palavras-chaves: Amazônia, determinações, estratégias produtivas, especificidades.

1. Doutor em Desenvolvimento Econômico, Espaço e Meio Ambiente pelo Instituto de Economia / Unicamp. Docente da Faculdade de Geografia FacGeo/ UFPA - Altamira e do programa de pós-graduação em Geografia PPGEO/UFPA - Belém. Líder do grupo de estudo Desenvolvimento e Dinâmicas Territoriais na Amazônia - GEDTAM. E-mail: herrera@ufpa.br.

2. Doutor em Administração de Empresas pelo Fundação Getulio Vargas - SP. Professor/ Pesquisador da Universidade Estadual de Campinas - Unicamp / Instituto de Economia. E-mail: peramos@eco.unicamp.br.

3. Mestre em Matemática e Estatística pela Universidade Federal do Pará. Funcionário público da Secretaria do Estado de Pesca e Aquicultura - SEPAq/PA, e consultor - Estatístico do Instituto Vitória Régia Para o Desenvolvimento da Amazônia e professor mestre da Faculdade Estácio do Pará. E-mail: ulisses08@gmail.com 


\begin{abstract}
Amazon is integrated into the national economy so that capital takes advantage of trade asymmetries not loyal and unequal. The exploitation of resources is being more intense, degrading the environment and worsening social problems. The imposition of the capital established relations, although it transformed the family agricultural production, and have not eliminated it, and this presents different forms of production and different social relations. Starting from this premise, this paper sought to understand the production strategies that constitute the family agricultural production in Southwestern area of Pará. The study was carried out in three municipalities: Pacajá, Ancient Settlement area; Anapu, PDS (Sustainable Development Project) area; and Senador José Porfirio, the project area of Conventional Settlement of Incra (National Institute of Colonization and Agrarian Reform). One hundred and fifty (150) families were researched_during the 2007-2008 agricultural cycle. Qualitative parameters (observation in loco) and quantitative (statistical analysis) were used as methodological procedures, which can elucidate a mosaic (trajectories, perspectives and trends) that comprises the diversity of family agricultural production that results of the different materials bases in which families have to establish their medium and long-term projects.
\end{abstract}

Key-words: Amazon, determinations, productive strategies, specificities.

Classificação JEL: Q12

\section{Introdução}

O estado do Pará representa importante papel no tocante à economia amazônica, tendo como principal setor econômico, o agropecuário. O setor emprega número significativo de pessoas, fazendo-se presente na maior parte do território. Nesse caso, não é priorizada a intepretação dos índices econômicos oficiais (IBGE), nos quais o setor Serviços é tido como responsável pela economia totalizante do estado, entendendo que essa atividade se faz centralizada na metrópole Belém, enquanto a produção agropecuária está descentralizada e dinamiza as atividades familiares não computadas pelos números oficiais.

O ponto focal da interpretação está nos produtores que se agrupam pela prática centrada na dinâmica familiar, que, sendo cooptados ou resistindo ao capitalismo na Amazônia, demonstram capacidade de transformação do espaço agrário com seus trabalhos. Esses sujeitos territoriais, a partir de seus meios de vida, garantem produção com menores impactos e riscos ambientais e expressiva geração de emprego e renda.

Apesar da imposição e dominação do capital nas relações estabelecidas na Amazônia, é preciso considerar a diversidade da produção agropecuária familiar. Nesta perspectiva, existem pro- dutores que não têm lucro e acumulação como objetivos principais em suas dinâmicas, muito embora mantenham relações econômicas com outros sujeitos no mercado.

A expressão produção agropecuária familiar é utilizada com o intuito de apontar que no contexto amazônico há uma realidade diversa, em que são encontradas famílias em condições camponesas, bem como grupos familiares legitimados pelas políticas públicas como agricultores familiares. Nesta perspectiva, objetiva-se, no escopo deste ensaio, compreender as estratégias familiares de produção na Amazônia.

A pesquisa foi realizada com produtores agropecuários familiares no Sudoeste Paraense, formado por duas microrregiões: a de Itaituba e a de Altamira, essa última conhecida por seus moradores como território da Transamazônica-Xingu. Dentre os quatorze (14) municípios que formam o Sudoeste Paraense, foram amostrados no estudo, 150 produtores dos municípios de Anapu, Pacajá e Senador José Porfírio.

A pesquisa se justifica por existirem diferentes formas de ocupação do espaço agrário amazônico. Uma área de colonização antiga, no município de Pacajá, que teve suas terras destinadas às famílias migrantes no período de abertura da rodovia Transamazônica (BR 230), de 1970 a 1980. Em Anapu, o estudo foi realizado em dois 
PDS (Projetos de Desenvolvimento Sustentável), criados em 2001, com o objetivo do uso sustentável da floresta; e, em Senador José Porfírio, a área de estudo foi organizada como Projeto de Assentamento Convencional do Incra (Instituto Nacional de Colonização e Reforma Agrária), com ocupação a partir de 2003. As propriedades, em sua maioria, obedecem ao módulo rural e em condições individuais.

\section{Fundamentação teórica}

O debate sobre a produção agropecuária familiar começa nas ciências sociais, tendo como foco a composição e os fatores determinantes na conduta dessa produção, passando pela reflexão sobre que tipo de produção familiar persiste no País. Em meio a esse debate, faz-se necessário compreender, a partir da realidade concreta, quais formas de produção agropecuária coexistem na Amazônia, ponderando as condições socioeconômicas desiguais, inerentes ao sistema capitalista em geral e do agrário, em particular, que ocasionam formas de produção diferenciadas.

Herrera (2012), fundamentado no texto de Lima (2005), destaca que as características da base material e as relações sociais que mantêm com o meio determinam condições objetivas de produção desiguais, de tal modo que estabelecem distintas lógicas de reprodução econômica e social. Esses objetivos conformam a finalidade das famílias e o tipo de racionalidade que passam a determinar as estratégias e táticas relativas à produção, estabelecendo diferentes níveis de acumulação e possibilidade de reprodução das unidades produtivas, condicionando diferentes formas de apropriação e uso dos recursos naturais.

Pokorny et al. (2010, p. 30), ao realizarem estudos sobre a diversidade de estratégias de meios de vida na Amazônia, identificaram grande diversidade de atividades realizadas pelas famílias e destacaram que "cada família segue uma estratégia específica, caracterizada por uma combinação complexa de diferentes atividades de produção e de geração de receitas".
Nessa perspectiva, entende-se que os conceitos utilizados no meio acadêmico, legitimados no Brasil, de certo modo, não representam as diversas realidades encontradas na Amazônia, deixando lacunas na compreensão das dinâmicas produtivas, principalmente no que se refere à composição de um universo heterogêneo, demandante de políticas públicas específicas que valorizem e respaldem seus meios de vida.

Neste texto, adota-se a expressão Produção Agropecuária Familiar para destacar que as relações socioprodutivas na Amazônia são as mais diversas, identificando-se desde a produção familiar, pautada em costumes e hábitos tradicionais próximos à lógica do campesinato clássico, alcançando até os sistemas que mantêm o núcleo familiar como gestor e executor das atividades com a interferência direta do capital, o que consolida a produção do ponto de vista capitalista.

A adoção da expressão não significa uma fuga dos conceitos já reconhecidos pela literatura, mas ao debater os problemas inerentes às terminologias se verifica, no caso do campesinato, de certo modo, o anacronismo. No que se refere à definição de agricultura familiar, identificam-se inconsistências e generalizações na tentativa de explicar as diversas formas de produção na Amazônia.

Neste sentido, Costa (2012, p. 212), ao tratar do campesinato na Amazônia, assume que estudar as diferentes formas de produção não é despolitizar a discussão acerca da lógica camponesa, mas, sim, requalificar a questão pautando a transformação em locus.

Assumindo os riscos das críticas, Herrera (2012) afirma que a "evolução" conceitual traçada na literatura brasileira, desde o camponês ao agricultor familiar, tem gerado incertezas nos debates acadêmicos e dificultado as tentativas de compreensão da realidade. Isso porque aquela definição sempre trouxe consigo o caráter do como fazer, o modo de vida e as reivindicações históricas, portanto, resultado da construção social ao longo do tempo.

A agricultura familiar, fazendo referências às lógicas que constituíam o camponês, foi definida politicamente. Assim, são tiradas as acepções 
reivindicatórias constituídas enquanto sujeito da história, fazendo-se sujeitos, de certo modo, passivos às políticas públicas generalizantes. Desse modo, deixam de ser consideradas as diferentes formas presentes da unidade de diversidade.

Fernandes e Leal (2002, p. 5-7), ao criticarem os teóricos da Agricultura Familiar, chamam a atenção de que não a destruição do campesinato, na verdade o esforço é de refutar o conceito. Essa afirmação tem o sentido de reforçar o uso da expressão campesinato na literatura. Já os teóricos da Agricultura Familiar partem do princípio que o camponês representa o velho, organização social atrasada, o arcaico, enquanto a agricultura familiar seria o moderno, o novo e o progresso.

Abramovay (2007, p. 21) defende a agricultura familiar a partir de três premissas: a integração no mercado: o papel determinante do Estado no desenvolvimento de políticas públicas e a incorporação de tecnologias. Essa reflexão alinha-se com a visão de Lamarche (1993, p. 22) que considera possível a transformação do camponês (modelo selvagem) para agricultura familiar (modelo ideal) numa tendência evolutiva.

Por sua vez, existem aqueles que defendem a utilização de camponês. Neste caso, vão buscar em Tepicht (1973) a explicação da permanência do conceito na atualidade ${ }^{4}$, o qual afirma que:

[...] o modo de produção camponês não é gerador de uma formação particular (tal como o capitalista), ele se incrusta numa série de formações, se adapta, interioriza de sua maneira as leis econômicas de cada uma e, ao mesmo tempo, com maior ou menor intensidade, imprime em cada uma delas a sua marca. Nisto reside [...] o segredo de sua surpreendente longevidade que inspira as predicações de sua perenidade (p. 19).

4. Dessa forma tem-se que o camponês não é apenas parte de uma "classe grosseira" (SHANIN, 1972 in PLOEG, 2006, p. 20), ele é igualmente parte de um mundo grosseiro e cruel. "Daí que a luta pela autonomia [...] em uma sociedade que condena pessoas à submissão, dependência, privação e as ameaças com a deterioração de seus meios de vida, torna-se central para "condição camponesa" (PLOEG, 2006, p. 20).
Fernandes e Leal (2002), ao tratarem a incongruência, afirmam ter distinção clara entre as duas definições, apesar de partirem da mesma lógica, a família como gestora e executora das atividades, na condição de trabalho. Os mesmos afirmam:

[...] o produtor familiar que utiliza os recursos técnicos e está altamente integrado ao mercado não é um camponês, mas sim um agricultor familiar. Desse modo, pode-se afirmar que a agricultura camponesa é familiar, mas nem toda a agricultura familiar é camponesa, ou que todo camponês é agricultor familiar, mas nem todo agricultor familiar é camponês. Criou-se assim um termo supérfluo, mas de reconhecida força teórico - política (FERNANDES e LEAL, 2002, p. 29).

Sem desmerecer ou desconsiderar o debate político e ideológico existente em torno dos conceitos, o que se propõe é compreender a produção agropecuária familiar como categoria social e econômica heterogênea do espaço agrário. A proposição tem o sentido de retomar os estudos e reflexões sobre as condições e as formas em que são desenvolvidas as atividades produtivas de sujeitos marcados pelas diferenças. E, contraria as afirmações e regras de conceito estático como parâmetro, já que as determinações reduzem para quem são, mas não estimulam compreender como esses de fato estão ou, ainda, quais as tendências desses no interior do agrário brasileiro e sobremaneira na Amazônia.

A opção pelo termo produção agropecuária familiar se faz na tentativa de buscar os detalhes no espectro de diferentes formas produtivas com possibilidade mantenedora da dinâmica tradicional de produção até as mais integradas e dependentes dos elos com os demais setores da economia nacional. Logicamente, as formas de produção familiar vão sendo alteradas à medida que há interferência do capital em sua dinâmica, o que vai condicionar a heterogeneidade já discorrida. Como bem frisou Kautsky (1968, p. 21), "é o modo de produção capitalista que domina a sociedade". 
Segundo Neves (1998, p. 15), “a história não eliminou a produção familiar das relações econômicas e sociais". Com base nesta afirmação, acredita-se que, pelo contrário, o capital tem se apropriado das formas de produção familiar como reguladora da economia nacional, sobretudo por garantir nessas relações taxas elevadas e mais facilitadas de lucro. Assim, repercute-se a afirmação de que, a depender dos interesses, o capital interfere em graus diferentes nas relações também diferenciadas.

Lamarche (1993, p. 21) menciona, em sua obra, sobre a capacidade de permanência e adaptação da produção agropecuária familiar, por ele definida agricultura familiar, afirmando que é sem dúvida graças a essa capacidade que "as explorações familiares que sempre se mantiveram em seus lugares são as que souberam - ou puderam - adaptar-se às exigências impostas por situações novas e diversas às instabilidades climáticas, à coletivização das terras ou à mutação sociocultural determinada pela economia de mercado".

A não utilização do termo agricultura familiar está pautado em Neves (2006, p. 2), quando destaca em afirmação que há esforço de (re)significação do termo na tentativa de associar à expressão seus sentidos positivos. A autora destaca que, nas últimas décadas do século passado, o termo ganhou vasta consagração, tornando-se difícil interpretar os diferentes signos associados à definição.

Neves (2006, p. 2) afirma ainda que, para além da eficiência institucional e operacional em defesa do termo agricultura familiar, fazia-se necessário discutir acerca da produção de imaginários ou sistemas de crenças para reorganizar a sociedade. Tal fato alterou a representação sobre si mesma, potenciando-a como portadora de possibilidades de ação política capaz de reordenar os sistemas relacionais.

A definição, em termos, vai responder às reivindicações feitas pelas lideranças sindicais e políticas por uma identidade representativa, motivos perceptíveis no caso do Brasil, pela disputa por espaços institucionais e políticos na dinâmica governamental. Nesse sentido, Neves (2006) afirma que:

À categoria agricultor familiar correspondem objetivos a serem alcançados [...]. Como categoria de mobilização política e enquadramento, está dotada da ambiguidade necessária à plasticidade da orquestração das diversas questões em jogo e dos direitos sociais, políticos e econômicos (p. 46).

Tais objetivos foram até certo ponto alcançados, sendo por sinal legitimado o conceito com aprovação no congresso, por meio da sanção à Lei n. 11.326 em 24 de julho de 2006, garantindo que a agricultura familiar fosse inserida nos estudos estatísticos oficiais do governo (IBGE, 2010).

A sistematização legal da definição acabou por reconhecer quem são os produtores familiares, mas não se preocupou em ponderar as especificidades de cada grupo que está contido na definição, desconsiderando os diferentes comportamentos e práticas que cada grupo estabelece ao se relacionar com os meios de produção e até mesmo entre si. Caracterizam, de certo modo, muito mais a necessidade de tornar iguais os diferentes do que necessariamente representar a unidade de diversidade que se faz a produção agropecuária familiar.

Essa constatação feita por Neves (2006) e explicitada aqui pode ser percebida no documento Censo Agropecuário 2006 - Agricultura Familiar, publicado pelo IBGE (2010), no qual faz-se ao apresentar as tabelas sistematizadas, justificando a solicitação feita pelo Ministério do Desenvolvimento Agrário (MDA) em denominar Agricultura. O texto explicativo elaborado pela equipe do IBGE poder ser analisado na íntegra a seguir.

Por conta de atender à demanda do Ministério do Desenvolvimento Agrário, o Censo Agropecuário 2006 adotou o conceito de "agricultura familiar", conforme a Lei n. 11.326, de 24 de julho de 2006, que estabelece as diretrizes para a formulação da Política Nacional da Agricultura Familiar e Empreendimentos Familiares Rurais. 
O conceito agricultura familiar não é inédito no arcabouço legal brasileiro. Conceitos muito próximos já vinham sendo utilizados no Programa Nacional de Fortalecimento da Agricultura Familiar - Pronaf, ou nos segurados especiais em regime de economia familiar da Previdência Social. O conceito também não é novidade na academia e foi utilizado em inúmeros trabalhos [...]. Entretanto, apesar de estes conceitos terem uma forte sobreposição de públicos, não são rigorosamente iguais, e suas delimitações dependem de análises precisas (IBGE, 2010, p. 15-16).

Não se faz possível uma leitura concreta das diferentes realidades que estão previstas na lei como componente do conceito, pois diz respeito a estruturas produtivas bem diferentes, muito embora tenham a família responsável pela condução da produção. Assim, concorda-se com Neves (2006) quando afirma que a agricultura familiar é:

Entendida como forma de organização da produção, seu estatuto é conceitual e, por princípio, universalizável, todavia, desde que capaz de dispensar os conteúdos situacionais e as condições de inserção em variadas formações socioeconômicas. Não pode, nesse plano, ser permutável com a categoria de mobilização e enquadramento político, nem englobar a multiplicidade de alternativas práticas de encapsulamento dos agricultores (p. 46).

Retomando a história das políticas públicas do País, percebe-se que o conceito agricultura familiar foi definido no período em que os movimentos sociais e líderes do governo buscavam mecanismos para financiar a produção no País, conquista atendida com o Decreto no 1.946 , de 28 de junho de 1996, o qual foi atualizado posteriormente pela Lei no 11.326 , de 24 de julho de 2006 (IBGE, 2010).

De acordo com Garcia Jr. e Heredia (2009, p. 215), a generalização do uso da categoria "agricultura familiar" foi largamente facilitada pela implantação, ainda nos anos 1990, do Pronaf, quando a política de crédito a juros reduzidos privilegiou de forma inédita uma faixa de agricultores de menos recursos econômicos, desvinculando-os dos grandes produtores que se haviam beneficiado, desde a modernização conservadora promovida pelo regime militar, de taxas de juros subsidiadas.

No entanto, os autores salientam que a utilização de um conceito vinculado à política pública seria um erro, pois se estaria diante da armadilha de perceber os agentes sociais apenas quando esses fossem nomeados pelo Estado, perdendo, com isso, o debate intelectual e instalando com facilidade o reducionismo ao invés de constituir instâncias de críticas das classificações do mundo social em vigor, de nomeações de novas possibilidades (GARCIA JR. e HEREDIA, 2009, p. 216).

Desse modo, o uso irrestrito do conceito agricultura familiar em estudos sobre a diversidade de produção que as famílias estabelecem no espaço agrário pode significar uma interpretação limitada quanto aos possíveis resultados encontrados nas relações sociais cotidianamente alteradas por um movimento natural ou por imposição externa aos seus meios de vida.

Nesse sentido, Pokorny et al. (2010) destacam em sua obra:

A grande diversidade das atividades empregadas pelas famílias mostrou claramente que as tentativas de classificá-las com base em somente um critério - por exemplo, em relação às suas estratégias de intensificação, extensificação ou migração (SCOONES, 1998; SWIT, 1998) ou grau de dependência dos recursos naturais (ELLIS, 2000) - simplificam demais o seu entendimento e correm o risco de gerar estereótipos incapazes de expressar adequadamente a realidade dos produtores (p. 32).

Ao tratar especificamente a situação do estado do Pará, Schimitz e Mota (2010, p. 25) destacam que, apesar do reconhecimento da expressão agricultura familiar no debate acadêmico e nas políticas públicas a partir dos anos 1990, a questão da diferenciação interna impõe algumas dificuldades. Os autores se questionam sobre "quais os critérios para identificar agricultores familia- 
res, por exemplo, no estado do Pará, com tipos tão diferentes".

Nesta perspectiva, Costa (2012), ao realizar o estudo comparativo entre microrregiões do Pará, aponta ter encontrado desde "evidencias da autonomia camponesa, nos moldes de Chayanov, nas áreas mais antigas, [...]. Ali onde a terra é 'cativa'" (p. 214), e até agricultura familiar que, sofrendo mudanças tecnológicas, substitui a shifting cultivation "por uma produção fundada nas culturas perenes" (p. 219).

$\mathrm{O}$ que se tem em comum entre as diferentes formas de produção é a base produtiva que se mantém pelos laços familiares, muito embora com dinâmicas diversas e interferência do capital estabelecendo condições diferenciadas que constituem a heterogeneidade de formas de produção. Nessa perspectiva, torna-se necessário compreender como a produção familiar é gestada e como se dá a interferência da dinâmica capitalista para, assim, mais ou menos ter condições de respaldar as inúmeras formas de produção expressadas no agrário amazônico.

A análise deste segmento social, diferente da agricultura patronal, mostrou, entre diversas escolas, controvérsias enormes. Uma parte dos cientistas considerava estes agricultores como empresários que pretendiam maximizar os lucros. Outros achavam que se tratava de um segmento caracterizado pela irracionalidade de gerenciamento das unidades de produção, pelo atraso tecnológico e por seu enraizamento profundo na tradição (SCHIMITZ e MOTA, 2010, p. 24).

Apesar de os termos campesinato, agricultor familiar e até pequeno produtor terem sido considerados nas interpretações brasileiras como conceitos de ação política, à época de predomínio de cada um no debate, tinham em comum o fato de descrever os mesmos segmentos e, por isso, muitas vezes, são considerados como sinônimos (SCHIMITZ e MOTA, 2010, p. 24), representando a dificuldade de tratamento aos diferentes sujeitos do agrário que, apesar de racionalidades econômicas e meios de vida diferentes, tem a família como determinante na produção agropecuária.
Independente do conceito ou definição assumido nos estudos, o importante é ter a interpretação do real papel da família na condução do processo de produção e como essa tem se comportado no contexto das transformações em função do determinismo do capital; desse modo, o fulcro é resgatar os debates sobre o adjetivo "familiar" como marcador de questões sociológicas, assim, passando "de algo dado e evidente para vínculo social singular a ser examinado em seu próprio contexto [...]. Estranhar o familiar (DA MATTA, 1978) é condição para buscar entender as redes assim designadas como relações sociais" (GARCIA JR. e HEREDIA, 2009, p. 216).

\section{Metodologia}

Na tentativa de compreender melhor a realidade dos produtores agropecuários, adotou-se a metodologia a partir da compreensão qualitativa subsidiada por procedimentos estatísticos, possibilitando estabelecer o Índice de Determinação da Produção Agropecuária Familiar (ID-PAF).

Para a composição do índice, foram selecionadas onze (11) variáveis, consideradas possíveis: Tempo de chegada; Condição de posse; Percentual de Floresta Nativa; Renda Bruta em relação à Renda Extra; Mão de obra familiar em relação à Força Trabalho contratado; Índice Trabalho; Índice Consumo; Capital produtivo; Índice de Diversificação; Produtividade da Superfície Agropecuária Utilizada e a Relação entre a produção consumida e produção vendida.

O teste, inicialmente, foi desenvolvido com todas as variáveis, no entanto, se percebeu que algumas delas estabeleciam baixa correlação com as demais. Buscando explicação com os fatores, foram mantidos, após alguns testes, apenas seis (6) das variáveis iniciais: Rendimento Agropecuário em relação à Renda Extra; Mão de obra familiar em relação à Força Trabalho contratada; Relação entre a produção consumida e produção vendida. Nota-se que essas três variáveis sempre estiveram presentes nas discussões feitas acerca da produção agropecuária familiar, balizando inclu- 
sive a definição adotada em lei. Além dessas três, foram mantidas as variáveis consideradas essências na determinação de produtores que estão na Amazônia, o Percentual de Floresta Nativa; o Índice de Diversificação e a Produtividade da Superfície Agropecuária Utilizada.

A composição dessas seis (6) variáveis possibilitou estabelecer um coeficiente de correlação acima de 30\%, indicando a possibilidade de utilização da Análise Fatorial. Tal constatação ocorre usando o teste de esfericidade de Bartlett em que se verificou a existência de correlação suficientemente forte para a análise como constatado na Tabela 1.

Observando-se a Tabela 1, nota-se que valor $p$ é de aproximadamente zero (0), ou seja, menor que o nível de significância $\alpha=5 \%$. Além disso, o teste que mede a adequação da utilização da Análise Fatorial para a base de dados, KMO (Kaiser-Meyer-Olkin), apresentou valor de 0,541, indicando a possibilidade da análise (valor acima de 0,50 ) para situação problema (NORONHA VIANA, 2005).

Utilizando as seis variáveis, a variância total mostrou explicação superior aos testes anteriores. $\mathrm{Na}$ Tabela 2, percebe-se que os valores em que os "próprios iniciais" igualam-se ao número de variáveis em análise (seis). Entretanto, apenas nos três primeiros fatores os valores são superiores a 1 .

É importante destacar, na Tabela 2, o percentual apontado pelos fatores na composição da variação: o Fator 1 é responsável por $25,12 \%$; Fator 2, por $21,72 \%$; e Fator 3, por 18,88\%, proporcionando acumulado de 65,717 de variação.

Desse modo, ao invés de utilizar os seis indicadores, foram usados apenas três (3) fatores, os quais garantiram a explicação por $65,717 \%$ da associação total entre os dados. Na Tabela 3, matriz dos fatores, gerada pelo método varimax, tem-se a apresentação das variáveis que compõem cada um dos três fatores utilizados na análise.

As cargas fatoriais são consideradas na correlação dos fatores com as variáveis estabelecendo coeficientes (podendo ser positivos ou negativos), necessitando, para estabelecer o índice, que fosse feita a redução a uma unidade comum, adimensional, de modo que foi feita a normalização das variáveis e, em seguida, calculados os indicadores de desempenho dos elementos.

Nota-se que o fator 1 tem, em sua composição, o percentual de floresta nativa; índice de diversificação e produtividade da superfície

Tabela 1. Teste KMO (Kaiser-Meyer-Olkin) e Bartlett's (38)

\begin{tabular}{llc}
\hline Kaiser-Meyer-Olkin Measure of Sampling Adequacy. & 0,541 \\
\hline \multirow{3}{*}{ Bartlett's Test of Sphericity } & Approx. Chi-Square & 62,120 \\
\cline { 2 - 3 } & DF & 15 \\
\cline { 2 - 3 } & P-value & 0,001 \\
\hline
\end{tabular}

Fonte: Elaboração do autor utilizando dados de pesquisa, ano 2007/2008.

Tabela 2. Método de extração: análise dos componentes principais

\begin{tabular}{|c|c|c|c|c|c|c|c|c|c|}
\hline & \multicolumn{3}{|c|}{ Valores próprios iniciais } & \multicolumn{3}{|c|}{$\begin{array}{l}\text { Extração soma dos } \\
\text { quadrados loadings }\end{array}$} & \multicolumn{3}{|c|}{$\begin{array}{l}\text { Rotação soma dos } \\
\text { quadrados loadings }\end{array}$} \\
\hline & Total & $\begin{array}{c}\% \text { de } \\
\text { variação }\end{array}$ & $\begin{array}{c}\text { Cumulat. } \\
\%\end{array}$ & Total & $\begin{array}{c}\% \text { de } \\
\text { variação }\end{array}$ & $\begin{array}{c}\text { Cumulat. } \\
\%\end{array}$ & Total & $\begin{array}{c}\% \text { de } \\
\text { variação }\end{array}$ & $\begin{array}{c}\text { Cumulat. } \\
\%\end{array}$ \\
\hline 1 & 1,694 & 28,230 & 28,230 & 1,694 & 28,230 & 28,230 & 1,507 & 25,116 & 25,116 \\
\hline 2 & 1,204 & 20,074 & 48,304 & 1,204 & 20,074 & 48,304 & 1,303 & 21,720 & 46,837 \\
\hline 3 & 1,045 & 17,414 & 65,717 & 1,045 & 17,414 & 65,717 & 1,133 & 18,881 & 65,717 \\
\hline 4 & 0,815 & 13,582 & 79,299 & & & & & & \\
\hline 5 & 0,717 & 11,956 & 91,256 & & & & & & \\
\hline 6 & 0,525 & 8,744 & 100,000 & & & & & & \\
\hline
\end{tabular}

Fonte: Elaboração do autor utilizando dados de pesquisa, ano 2007/2008. 
Tabela 3. Matriz dos fatores rotacionados, método varimax

\begin{tabular}{lccc}
\hline \multicolumn{1}{c}{ Variáveis } & \multicolumn{2}{c}{ Fatores } \\
\cline { 2 - 4 } & Fator 1 & Fator 2 & Fator 3 \\
\hline Percentual de floresta nativa & $\mathbf{0 , 7 0 8}$ & $-0,001$ & $\mathbf{0 , 8 3}$ \\
Renda bruta em relação a renda extra & 0,119 & 0,023 & 0,376 \\
Mão de obra familiar em relação a foca trabalho contratado & $-0,127$ & $\mathbf{0 , 7 3 4}$ & 0,215 \\
Índice de diversificação & $\mathbf{0 , 6 2 4}$ & 0,399 & $-0,381$ \\
Relação entre a produção consumida e produção vendida & 0,152 & $\mathbf{0 , 7 6 9}$ & 0,265 \\
Produtividade da superfície agropecuária utilizada & $\mathbf{0 , 7 5 0}$ & $-0,111$ & \\
\hline
\end{tabular}

Fonte: Elaboração do autor utilizando dados de pesquisa, ano 2007/2008.

Tabela 4. Relação dos fatores na determinação das faixas do ID-PAF

\begin{tabular}{|c|c|c|c|c|c|c|}
\hline \multirow[b]{2}{*}{ Faixas ID-PAF } & \multicolumn{3}{|c|}{$\begin{array}{c}\text { Fator I } \\
\text { Uso dos recursos naturais } \\
\end{array}$} & \multicolumn{2}{|c|}{$\begin{array}{c}\text { Fator II } \\
\text { Mão de obra e consumo familiar }\end{array}$} & \multirow{2}{*}{$\begin{array}{c}\text { Fator III } \\
\text { Relação renda } \\
\begin{array}{c}\text { Relação renda } \\
\text { bruta e renda } \\
\text { extra }\end{array}\end{array}$} \\
\hline & $\begin{array}{l}\text { Percentual de } \\
\quad \text { floresta }\end{array}$ & Diversificação & $\begin{array}{c}\text { Produtividade } \\
\text { da superfície } \\
\text { agropecuária } \\
\text { utilizada }\end{array}$ & $\begin{array}{l}\text { Relação mão de } \\
\text { obra familiar e a } \\
\text { força de trabalho } \\
\text { contratada }\end{array}$ & $\begin{array}{c}\text { Relação produção } \\
\text { consumida e } \\
\text { produção } \\
\text { vendida }\end{array}$ & \\
\hline $0,60-1,00$ & +++ & +++ & +++ & +++ & +++ & +++ \\
\hline $0,40-0,60$ & +++ & +++ & ++ & +++ & +++ & ++ \\
\hline $0,30-0,40$ & +++ & ++ & ++ & ++ & ++ & + \\
\hline $0,20-0,30$ & ++ & + & + & + & + & + \\
\hline $0,00-0,20$ & + & + & + & + & + & + \\
\hline
\end{tabular}

+++ Alta intensidade; + + Média intensidade; + Baixa intensidade.

Fonte: Elaboração do autor utilizando dados de pesquisa, ano 2007/2008

agropecuária utilizada, por isso foi definido como fator - uso dos recursos naturais. $\mathrm{O}$ fator 2 , por sua vez, corresponde às variáveis que relacionam a mão de obra familiar e contratada para o estabelecimento e a relação da produção consumida e vendida pelos produtores, sendo caracterizado como fator - mão de obra e consumo familiar. Por fim, o fator 3 apresenta a variável relação de renda bruta agropecuária e as rendas extras do ciclo agrícola.

A etapa seguinte foi hierarquizar e agrupar os escores fatoriais por critérios, tais como o de melhor desempenho e o da dispersão em torno da média aritmética. É possível construir, assim, intervalos de classes que variam do baixo ao alto potencial de desenvolvimento; no caso da análise feita com os produtores, aqueles que tendem ao baixo potencial (0) têm menor determinação das condicionantes consideradas essenciais na produção agropecuária familiar, logo, no oposto, tendendo ao alto potencial (1) estaria o produ- tor agropecuário familiar ideal considerando-se as variáveis elencadas nesse estudo. Na Tabela 4 esboça-se a relação dos fatores com as faixas do índice (ID-PAF) estabelecido.

Como visto na Tabela 4, os fatores correspondem com intensidades diferenciadas nas faixas estabelecidas. Por exemplo, para haver o caso de um produtor agropecuário familiar ideal, faixa entre 0,6 e 1, faz-se necessário que o mesmo tenha a correspondência com todos os fatores com alta intensidade, enquanto os produtores que estão tendendo ao formato patronal ou pelo menos estão na última faixa estabelecida para produtores familiares apresentaram baixa intensidade em todos os fatores utilizados para esquematização do índice estatístico.

A partir dessa esquematização estatística foi possível estabelecer um ranking com os cento e cinquenta (150) produtores acompanhados durante a pesquisa, como pode ser observado na Tabela 5 . 
Tabela 5. Tipos de produtores agropecuários familiares por faixa do ID-PAF

\begin{tabular}{|c|c|c|c|c|c|c|c|c|}
\hline \multirow{2}{*}{$\begin{array}{l}\text { Faixas } \\
\text { (ID-PAF) }\end{array}$} & \multicolumn{2}{|c|}{$\begin{array}{c}\text { Anapu } \\
\text { (PDS) }\end{array}$} & \multicolumn{2}{|c|}{$\begin{array}{c}\text { Pcajá } \\
\text { (Colonização antiga) }\end{array}$} & \multicolumn{2}{|c|}{$\begin{array}{c}\text { Senador José Porfírio } \\
\text { (Assentamento) }\end{array}$} & \multicolumn{2}{|c|}{ Total geral } \\
\hline & $N^{o}$ & $\%$ & $N^{o}$ & $\%$ & $N^{\underline{o}}$ & $\%$ & $N^{o}$ & $\%$ \\
\hline Até - 0,2 & 5 & 6,4 & 7 & 28,0 & 1 & 2,1 & 13 & 8,7 \\
\hline $0,2 \mid---0,3$ & 37 & 47,4 & 18 & 72,0 & 13 & 27,7 & 68 & 45,3 \\
\hline $0,3 \mid---0,4$ & 31 & 39,7 & 0 & 0,0 & 26 & 55,3 & 57 & 38,0 \\
\hline $0,4 \mid---0,6$ & 5 & 6,4 & 0 & 0,0 & 7 & 14,9 & 12 & 8,0 \\
\hline Total geral & 78 & 100,0 & 25 & 100,0 & 47 & 100,0 & 150 & 100,0 \\
\hline
\end{tabular}

Fonte: Elaboração do autor utilizando dados de pesquisa, ano 2007/2008.

A partir dos dados de pesquisa, os produtores foram organizados em grupos, considerando-se que as condições socioeconômicas e o ambiente em que estão as famílias traduzem evoluções distintas e situações desiguais de capitalização (FAO/ INCRA, 1995, p. 24).

Ratifica-se que não há uma tipologia padrão, ou seja, um agrupamento de produtores que seja reconhecido como ideal. Segundo pressuposto do guia metodológico publicado pela $\mathrm{FAO} /$ Incra (1995, p. 25) e muito utilizado em pesquisas comprometidas com o agrupamento de produtores, não há uma tipologia válida para qualquer situação, mas é a realidade que apresenta os critérios relevantes para se operacionalizar o estudo das características dos produtores.

Na verdade, tem-se a assertiva de que o agrário amazônico possui vasta diversidade de produção e relações sociais, que dificilmente terá sua representação de maneira correta e adequada em uma única expressão ou definição. Entende-se que cada empresa patronal ou a família partem de estratégias específicas para desempenharem suas atividades de produção, muito embora estejam próximas umas das outras em relação aos objetivos traçados.

Vários estudos e diagnósticos já foram realizados na tentativa de compreender as diferentes categorias ou formas de produção no Brasil e na Amazônia. No entanto, não se consegue elencar um dentre os muitos trabalhos já realizados que explicite toda diversidade da produção que compõe o agrário brasileiro ou amazônico em específico, não por falta de méritos, mas sim porque a ampla realidade não se faz perceptível por completo em um estudo.
É na realidade concreta que se apreendem as diferenças que dão forma e dinamização à produção agropecuária familiar, principalmente ao se tratar da Amazônia, território de conflitos e de sujeitos com distintas racionalidades que, com o tempo, são submetidos à tentativa de homogeneização das relações sociais e de produção por parte do capital. Portanto, representar a diversidade do agrário, assumindo algumas formas de produção para exemplificar heterogeneidade estará sempre susceptível a erros.

Assume-se antecipadamente o exercício como um ato simplificador, mas, para melhor se aproximar da realidade, adotou-se o diagnóstico com procedimentos metodológicos ponderando, principalmente: a) as situações ecológicas e socioeconômicas dos produtores; $b$ ) os principais sistemas de produção (práticas e técnicas); c) os principais problemas e potencialidades e d) o engajamento dos produtores com outros agentes (comércio, bancos, agroindústrias, poder público etc.) (FAO/INCRA, 1995, p. 7).

A maioria dos estudos sobre o agrário no Brasil tem apresentado a análise a partir da dicotomia Agricultura Patronal e Agricultura Familiar. O processo dicotômico de análise deixa a desejar ao desconsiderar os elementos da totalidade e da diversidade devido aos parâmetros adotados nos estudos. Bem verdade, deve-se ter o estudo da realidade concreta para precisar as formas e relações de produção, e a posteriori aproximar-se dos fenômenos inerentes a cada forma de produção para compreendê-las em suas especificidades.

No caso dos estudos a partir da dicotomia, muito já se fez para entender as repulsões e rela- 
ções estabelecidas entre as duas formas de produção, no entanto, os exercícios são constituídos, normalmente, como um quadro comparativo que sobremaneira omite realidades complexas existentes nos dois "mundos", principalmente quando comparadas apenas as vantagens e desvantagens de uma forma de produzir em relação à outra.

Apesar de não esboçarem as características específicas que compõem as diferentes realidades produtivas, não há demérito nos estudos realizados, já que a maioria deles subsidia a política de defesa de uma ou outra forma de produção, servindo muito mais para dar visibilidade e respaldar a necessidade de atendimento por parte dos governos do que a compreensão detalhada do agrário brasileiro.

Na Figura 1A, anexa, faz-se a tentativa de visualizar algumas diferentes formas presentes no interior da Produção Agropecuária Patronal e da Produção Agropecuária Familiar, enfatizando na esquematização características gerais de cada grupo e a tendência das formas de produção quanto à interferência do capital. Importante frisar que se assume o risco ao fazer a simplificação. A esquematização serve para ilustrar e enfatizar algumas das possíveis formas que compõem a heterogeneidade do agrário amazônico. As informações que subsidiaram a sistematização têm origem no estudo de Blum (2001), por considerar que as formas por ele trabalhadas estão mais próximas, em linhas gerais, da realidade percebida na Amazônia.

A esquematização, a bem da verdade, serve para ilustrar que há situações específicas no contexto das relações de produção do agrário a depender da interferência do capital e que essas ocorrem ultrapassando os limites dos dois polos (Patronal e Familiar) como normalmente são realizados os estudos do agrário brasileiro. Assume-se, desse modo, a máxima de que os interesses e condições do capital podem estabelecer sempre uma nova forma de relação social e produtiva mantendo as formas anacrônicas na perspectiva de se expandir concentrando.

O exercício explicita o esforço de concretizar a reflexão feita sobre as diferentes formas existen- tes na realidade vivenciada. Ressalta-se que, além das formas indicadas aqui, existem outras formas de produção (índios, remanescentes de quilombo e extrativistas) merecedoras de ressalvas quando interpretados seus modos de vidas em relação às categorias apresentadas na sistematização.

$\mathrm{Na}$ caracterização feita por Blum (2001, p. 70-72), foram elencadas cinco formas de produção, sendo elas: Propriedade patronal latifundiária; Empresa patronal capitalista; Empresa familiar consolidada; Empresa familiar em transição e, por fim, Propriedade familiar periférica ou de subsistência. Todas elas foram usadas na sistematização, muito embora a descrição adotada não seja idêntica à de Blum. As alterações tiveram a intenção de compreender melhor o cotidiano percebido com as pesquisas na Amazônia.

Há ressalva quanto à última categoria adotada: ao invés de considerar como "propriedade familiar periférica ou de subsistência", é tratada pela terminologia "produção familiar tradicional" por considerar que essas são formas que mantêm suas características tradicionais de produção, mas nem sempre estão voltadas, única e exclusivamente, para a subsistência da família. Além disso, ao invés de adotar a expressão propriedade para categoria familiar em transição, optou-se por identificá-las por Produção Familiar em Transição. A seguir, tem-se o entendimento dado a cada uma das definições.

a) Propriedade Patronal Latifundiária - o proprietário não mora na área, caracterizada por um conjunto de terra de grande extensão, podendo ser improdutiva ou explorada por frações de capital com técnicas predatórias, baixa ou nenhuma tecnologia adotada. Normalmente, o proprietário não depende do retorno financeiro desse sistema produtivo; assim, a força de trabalho é mínima e em condição contratual (profissionalizante).

b) Empresa Patronal Capitalista - são unidades de produção que possuem mais do que 200 ha de terra, contam com alta tecnologia (mecanização total da produção e utilização racional de insumos moder- 
nos). Têm a produção especializada e em grande escala por meio da contratação de força de trabalho qualificada, voltada para o mercado, com gerenciamento capacitado para recorrer ao sistema creditício quando necessário, e a grande parte apresenta dependência de capital externo à produção ${ }^{5}$.

c) Empresa Familiar consolidada - unidades de produção que possuem normalmente porção de terra inferior a quatro módulos rurais com capital de exploração disponível. Além de recorrerem ao sistema bancário quando necessitam de capital, detêm implementos tecnológicos em parte dos sistemas de produção e adotam insumos modernos nas práticas e manejos das atividades agropecuárias. Estas são semi-intensificadas com o objetivo da produção voltado para o mercado. A família mora e gerencia a unidade de produção como também executa as atividades, contratando força de trabalho durante todo o ciclo agropecuário para realizar a produção.

d) Produção Familiar em Transição - é unidade de produção que possui no máximo quatro módulos rurais, dependente de baixo capital exploratório. Busca a diversificação na produção de maneira que a família ainda se consolida como mão de obra essencial. Contrata força de trabalho em períodos esporádicos e sempre em menor quantidade que o total da mão de obra familiar destinada às atividades. Tem um sistema de comercialização fragilizado, devido à escala de produção não ser tão elevada. Quando acessa o crédito bancário é sempre em proporções pequenas em relação às demais unidades de produção do setor, sendo atendida por linhas especiais de financiamento.

5. Essas duas categorias apresentadas até aqui não diferem das usadas por Costa (2000) ao expor os sujeitos patronais (capitalistas). A diferença é marcada ao estabelecer as categorias existentes enquanto produtores familiares.
O fato de ser considerada em transição não significa que há um único sentido; muitas famílias na Amazônia retomaram ao longo do tempo suas formas tradicionais, seja por opção (ao se distanciar das relações de mercado) ou por imposição do contexto, não tendendo à forma consolidada.

e) Produção Familiar Tradicional ${ }^{6}$ - são unidades caracterizadas pelo uso de áreas no máximo iguais ao módulo rural, produzem de maneira diversificada e em pequena escala, comercializando, na maioria das vezes, o excedente de produção - economia do excedente. A família reside na área e compõe a mão de obra para as práticas e manejos das atividades agropecuárias, mas não deixando de contar com a força de trabalho externa. A relação de pagamento, em sua maioria, se dá com trocas de serviços ou bens e em número menor do que a força destinada pela família ao longo da produção. Não são dependentes de maquinários ou insumos modernos para produzir e adotam práticas tradicionais na exploração dos meios de produção. O sustento da família tem sua origem basicamente no próprio sistema de produção, sem capital e de maneira muito incipiente dependente do crédito bancário; quando usado é único e exclusivamente por intermédio de instituições jurídicas legais, como sindicatos e associações.

Uma observação a ser feita é que essas formas de produção não estão estáticas e nem tão pouco isoladas no tempo e no espaço. Compõem um conjunto dinâmico, que no seu interior estabelecem relações e repulsões, podendo, desse modo,

6. A expressão tradicional utilizada aqui se refere ao modo de vida próximo à condição camponesa, ou seja, mantendo traços da lógica histórica da família (tradição) produzir no campo; portanto, não se replica a populações tradicionais que detêm estratégias de produção diferentes das expostas neste ensaio. 
encontrar diferentes formas de produção familiar tradicional que mantenham a essência da descrição, mas com elementos que as distinguem internamente umas das outras.

\section{Resultados e discussões}

Na Tabela 5, uma condição chama a atenção e aguçou ainda mais a realização da análise quantitativa conjugada à interpretação qualitativa das informações. Entre os produtores acompanhados, o coeficiente mais próximo do considerado ideal (1) pelos parâmetros delimitados no estudo foi próximo de 0,56 , ou seja, apenas $56 \%$ do que se considerou como determinante à condição de produtor agropecuário familiar. Adianta-se que há influência de duas variáveis na análise fatorial, a participação da renda extra em relação ao rendimento agropecuário e o percentual de floresta nativa registrado nos estabelecimentos.

A renda extra em muitos estabelecimentos foi considerada como essencial para a reprodução familiar, fazendo-se frequente seu uso com valores acima do rendimento gerado pela produção agropecuária. Essa situação foi principalmente encontrada nas famílias mais jovens e que, por estarem começando seus sistemas de produção, tiveram que recorrer à venda de força de trabalho e/ou conta com apoio institucional para viabilizarem suas permanências no espaço agrário.

O percentual de floresta nativa em determinados estabelecimentos condicionou alguns produtores à baixa variação no índice de determinação. Essa variável influenciou significativamente na determinação das famílias consideradas antigas, devido ao tempo de permanência e à quantidade de abertura de floresta, principalmente nas áreas com pastagens nos estabelecimentos. Assim, por mais que os produtores adotassem uma dinâmica próxima do ideal considerando os demais fatores, o baixo percentual de floresta nativa contribuiu no enquadramento geral dos produtores segundo o índice estabelecido.

Tal situação pode ser percebida ao analisar, na Tabela 5, os produtores familiares que estão em
Pacajá (Colonização Antiga), por apresentarem valores elevados com outras rendas e devido ao desmatamento gerado pelo tempo em que estão nas propriedades, foram encontrados entre as faixas I e II no ranking do ID-PAF. Das vinte e cinco (25) famílias acompanhadas, $72 \%$ estão na faixa II e, $28 \%$, na faixa I, e apresentaram uma configuração no sistema de produção tendendo à estrutura menos familiar.

Apesar de a família manter a condução e execução das atividades, as relações sociais e a dinâmica produtiva foram alteradas, passando a depender das relações externas e de maior contratação de força de trabalho nas atividades agropecuárias. A produção passa ser mais especializada, com no máximo três atividades, permanecendo principalmente a criação bovina e o cultivo da lavoura cacaueira, o que dinamiza um sistema de produção voltado para o mercado, consequentemente, distanciando da produção para a família.

Esse distanciamento é interpretado como menor autonomia na hora de determinar a produção e como produzir, pois os núcleos familiares, ao invés de adotarem estratégias diretas de abastecimento familiar, começam a pensar e a executar a produção pautada na demanda de mercado. Mesmo garantindo a reprodução familiar, são percebidas mudanças principalmente na quantidade de força de trabalho destinada e na tentativa de maior volume de produção possível, apesar de núcleos familiares compostos por números pequenos de membros, rompendo a lógica de autoexploração prevista por Chayanov (1974).

Noutro extremo, próximo do que seria uma produção agropecuária familiar, considerando-se os parâmetros aqui adotados, foram encontradas apenas doze (12) famílias, contabilizando $8 \%$ do total de famílias na faixa IV, entre 0,4 e 0,6 do ID-PAF, sendo, inclusive, o percentual menor do que o registrado para as famílias que estão na faixa I $(8,7 \%)$. Os produtores que tiveram o perfil mais próximo do esperado dentro da análise estatística foram registrados nos municípios de Anapu, cinco (5) famílias e, em Senador José Porfírio, as outras sete (7) famílias que se aproximaram dos critérios estabelecidos para o estudo. 
O grande percentual de famílias foi caracterizado nas faixas II e III, variando entre 0,2 e 0,4 na escala do ID-PAF, apresentando, dentre elas, uma diversidade de racionalidades e formas de conduzirem os seus estabelecimentos que chamou a atenção durante a pesquisa, afinal, mais uma vez se coloca em questão o fato de que, apesar de o capital tentar enquadrar as diferentes formas de produção no processo de homogeneização, percebe-se que há uma heterogeneidade que se perpetua.

Dessas famílias (107 do total amostral - 71,3\%), foram encontradas 50 na faixa II e, com isso, caracterizou 46,7\% das famílias, localizadas em Anapu, $74 \%$ do total, e, em Senador José Porfírio, onde foram encontradas $26 \%$ das famílias nessa faixa do ID-PAF. Os outros 53,7\% foram encontrados divididos, sendo o maior percentual em Anapu, totalizando $54,3 \%$ das famílias na faixa III (entre 0,3 e 0,4 ) do ID-PAF, enquanto os $45,7 \%$ eram residentes de Senador José Porfírio.

Utilizando-se de uma esquematização, apresentada anexo - Figura 1A, são organizadas, na Tabela 6, as famílias acompanhadas na pesquisa, considerando suas características gerais e o grau do ID-PAF. A composição dos dados quantitativos com uma intepretação qualitativa da realidade proporcionam uma interpretação subjetiva sobre a mesma, mas se buscou o agrupamento da melhor forma possível, omitindo inicialmente as informações de quem eram os produtores e quais os municípios que residiam durante a análise, e só depois do agrupamento feito foram identificadas as famílias caracterizadas dentro de cada categoria e a qual o município (tipo de ocupação da terra) pertenciam.
Pode-se notar, na Tabela 6, que das cento e cinquenta (150) famílias acompanhadas, ocorreu a distribuição das mesmas em $30 \%$ em Empresa Familiar Consolidada, 24,6\%, em Produção Familiar em Transição e 45,4\%, em Produção Familiar Tradicional. É interessante verificar a participação das famílias nessas categorias quanto ao ID-PAF, notadamente, as famílias que se enquadraram na faixa I (entre 0 e 0,20 ) do índice estiveram justamente nas categorias que vêm historicamente mudando a lógica de produção, saindo da condição propriamente tradicional para estabelecerem relações capitalistas, estando, assim, mais vulneráveis às suas interferências.

Das famílias que estão na faixa I do índice, seis (6) foram consideradas empresas familiares consolidadas, e os fatores que determinaram isso foram os valores de rendas extras, principalmente a proporção de força de trabalho vendida por familiares e a realização de comércios variados, o valor do capital produtivo em infraestrutura e a baixa diversificação da produção, essa quase exclusivamente para o mercado. As famílias consideradas mais especializadas apresentaram distanciamento da condição familiar tradicional (ideal 1), estão todas situadas em Pacajá (colonização antiga), contam com título da terra e estão, em média, há mais de vinte (20) anos nos estabelecimentos.

As outras sete (7) famílias da faixa I foram agrupadas na produção familiar em transição. A produção em transição é aquela que de certo modo se distancia um pouco do idealizado para produção familiar, mas não chegou a se consolidar enquanto empresa familiar, principalmente porque as rendas extras originam-se de benefí-

Tabela 6. Categorias da produção agropecuária familiar por faixa do ID-PAF

\begin{tabular}{lcccc}
\hline \multirow{2}{*}{ Faixas do ID-PAF } & \multicolumn{4}{c}{ Produção agropecuária familiar } \\
\cline { 2 - 5 } & Empresa familiar consolidada & Produção familiar em transição & Produção familiartradicional & Total \\
\hline Faixa I (0 a 0,20) & 6 & 7 & 0 & 13 \\
Faixa II $(0,20$ a 0,30) & 21 & 18 & 29 & 68 \\
Faixa III $(0,30$ a 0,40) & 15 & 10 & 32 & 7 \\
Faixa IV (0,40 a 0,60) & 3 & 2 & 68 & 12 \\
Total & 45 & 37 & 750 \\
\hline
\end{tabular}

Fonte: Elaboração do autor utilizando dados de pesquisa, ano 2007/2008. 
cios ou apoio institucional, podendo até serem caracterizadas de outra forma (tradicional) caso não tenha mais essas rendas. Além disso, os valores em capitais produtivos e os rendimentos são bem inferiores àqueles encontrados nas famílias consolidadas como empresa no espaço agrário.

Constatou-se que essas famílias são mais vulneráveis às interferências do capital, principalmente por meio da subsunção da família às atividades degradantes de trabalho com baixos retornos financeiros e por normalmente venderem seus produtos abaixo dos preços médios de mercado, sofrendo com a apropriação do capital no momento da circulação da mercadoria.

Fato marcante entre as famílias da faixa em condição de empresa familiar consolidada e em transição, principalmente as que receberam recursos financeiros via crédito governamental. Portanto, tiveram, num momento da história, a interferência direta de políticas governamentais em seus sistemas de produção, de maneira significativa para menor diversificação da produção e à necessidade de relações com os capitalistas mais próximas na busca de melhor participação nos mercados locais.
Na Figura 1, torna-se evidente a concentração das famílias nas faixas II e III do ID-PAF, constatando-se que essas estão expressivamente em condições de produtores familiares tradicionais $-40 \%$ das famílias acompanhadas com a pesquisa foram verificadas nessa condição. Outro dado importante notado na Figura 1 é o fato de terem sido encontradas famílias nas faixas II e III consideradas empresas familiares consolidadas, isso por caracterizar que as famílias não precisam abandonar suas lógicas, ou seja, não se distanciarem de suas formas tradicionais para se consolidarem no espaço agrário.

As empresas familiares consolidadas que estão nas faixas II e III somaram $24 \%$ do total de famílias que participaram da pesquisa. $\mathrm{O}$ marcante em suas estruturas é que, ao mesmo tempo em que participaram diretamente do mercado, receberam crédito e estabeleceram relações de trabalhos além do familiar, vendendo ou contratando força de trabalho. Essas famílias mantiveram suas características quanto às relações internas, lógica familiar, e uma dinâmica de produção com menos dano ao meio ambiente do que as alocadas na faixa I, tendo por sinal grande

Figura 1. \% produtos por faixa do ID-PAF e categoria de produção agropecuária familiar

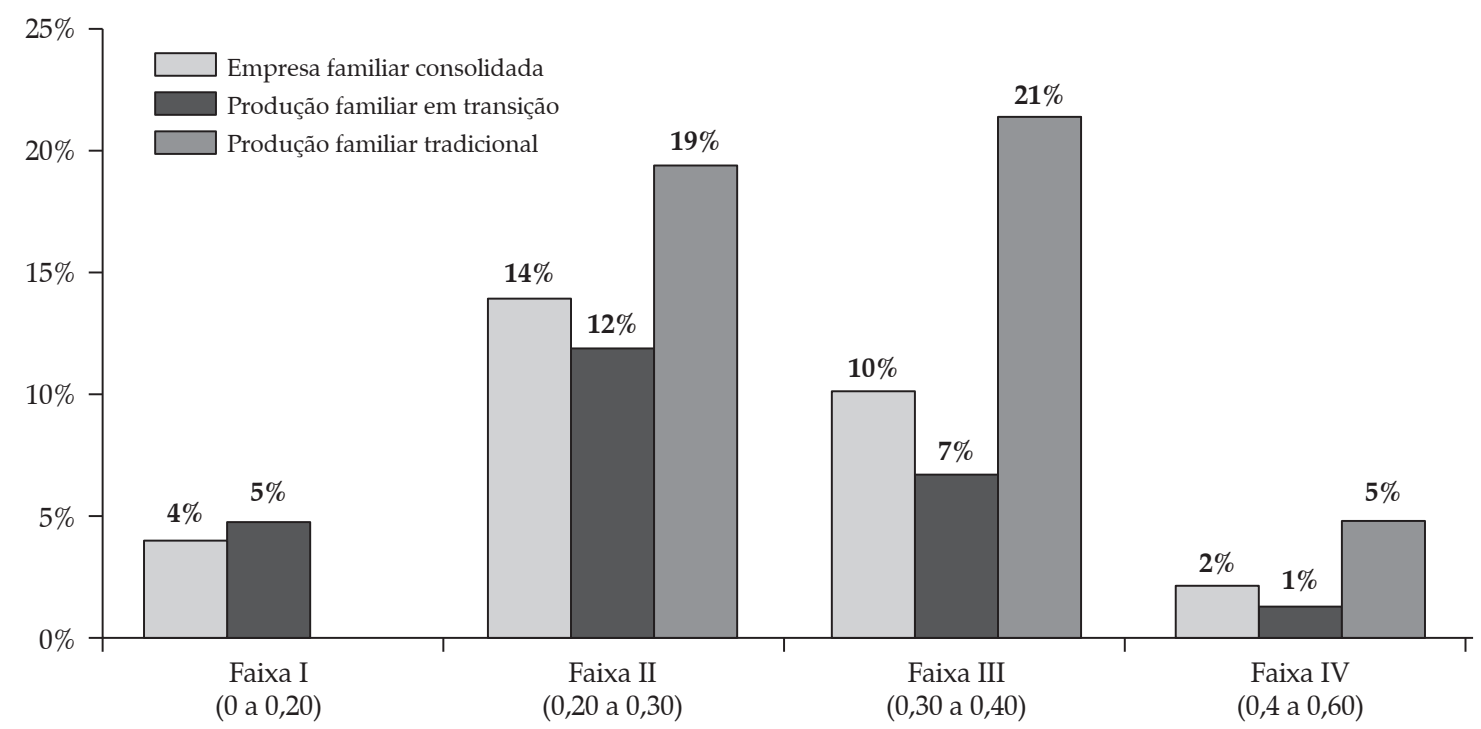

Fonte: Elaboração do autor a partir da pesquisa de campo, ano 2007/2008. 
percentual de floresta. Além disso, têm considerável grau de aproveitamento da superfície agricultável, apresentando diversidade com quintais florestais, sistemas agroflorestais e as lavouras temporárias e perenes praticadas por membros das famílias, assim como as pequenas e médias criações.

Os 19\%, produção familiar em transição, que somam ao total de $83 \%$ (faixa II e III) das famílias que participaram da pesquisa, apresentaram características próximas das famílias consideradas tradicionais. Embora tendam ao maior engajamento com suas produções, principalmente a lavoura cacaueira, com atravessadores e comerciantes, a estrutura que se configura nos estabelecimentos é de melhor aproveitamento da superfície agricultável, aumentando e intensificando o uso da área com a lavoura cacaueira e ampliação dos sistemas agroflorestais.

Muitas famílias que estavam nessa condição e se consolidaram como empresa familiar mantiveram a estratégia de contenção ao desmatamento e aproveitamento de área para diversificação de produção, devido às limitações colocadas para a criação de gado bovino e à crescente demanda por produtos agrícolas na região.

As famílias da faixa IV do índice de determinação que estão distribuídas entre os municípios de Anapu e Senador José Porfírio representaram um percentual pequeno entre o número total de famílias acompanhadas, e essas estiveram de acordo com a interpretação feita, agrupadas nas três categorias de produtores familiares organizadas durante a pesquisa.

Essas famílias, faixa IV, eram $2 \%$ empresa consolidada, $1 \%$, produção agropecuária em transição e 5\%, produção familiar tradicional. Apesar de baixos os valores em relação ao montante de famílias participantes, essas têm características que atendem o esperado ao iniciar a pesquisa. São famílias que estivessem vivendo e trabalhando, tendo seus meios de vidas mantidos face às transformações e interferências externas às suas lógicas, mas que pudessem mostrar resultados satisfatórios dentro da concepção de sistemas produtivos sem degradar o meio ambiente, pro- duzindo o suficiente para a reprodução familiar e participando do mercado com seus produtos excedentes.

Atualmente, não há famílias isoladas ou autossuficientes num território que não sofram a interferência pela expansão do capital. Contudo, foi possível encontrar e acompanhar famílias que resistem às perversidades e oportunismos dos agentes do capital, mesmo que para isso tenham que redimensionar seus sistemas de produção e estarem constantemente repensando suas estratégias de continuidades.

Esse reduzido número de famílias somado às famílias que estão nas faixas II e principalmente na III, configuram sujeitos do território que são devidamente estimulados a partir de suas realidades, conscientizando-os de que é possível produzir e melhorar a qualidade de vida sem necessariamente levar ao extremo o uso dos recursos naturais sem se submeter à lógica de que o ideal está no máximo lucro possível, acumulação de capital.

Para isso, equívocos históricos precisam ser reparados, e deve ser dada a atenção devida às diferentes realidades da produção agropecuária que permanecem com estratégias familiares, com suas lógicas em meio à constante transformação. Dentre os problemas mais graves percebidos está a dependência das rendas externas que resultam quase sempre da impossibilidade de se produzir o necessário para sustentar a família e comercializar para sanar as necessidades básicas e da capacidade de produção.

A dependência de rendas extras está diretamente ligada a dois outros fatores influentes na manutenção e melhoria de um sistema de produção familiar: o tamanho e qualidade da área usada na produção e a distância do estabelecimento dos produtores.

No primeiro caso, tamanho e qualidade da área usada para produção, ficou constatado que áreas pequenas, minifúndios, são inviáveis para que as famílias possam trabalhar. Isso não quer dizer que se deva ter vastas porções de terras por famílias, mas, devido ao fato de as famílias serem numerosas e pensarem em repartir a terra 
para fixarem os filhos no local, 20 ha, por exemplo, se torna pequeno, principalmente a depender da qualidade do solo. Tal fato foi verificado ao comparar as famílias que estão em Anapu com as residentes em Senador José Porfírio. Apesar do período de permanência próximo, os produtores desse município, por terem a certeza de ter 80 ha, em média, mesmo dependendo do documento oficial do Incra, estão organizando o estabelecimento para um longo período de vida no local.

A estratégia não representou aumento no desmatamento da área, mas, sim, intensificação do uso da terra com lavouras permanentes e criações de médio e pequeno porte, não deixando de ter, em determinados casos, o rebanho de vaca leiteira. Enquanto as famílias que estavam no Anapu (PDS) apresentaram piores indicadores sociais, principalmente quanto à moradia e grau de escolaridade, e apesar de muitas estarem adotando os quintais florestais e os sistemas agroflorestais como atividade de produção, ainda há constante saída de membros familiares para a venda de força de trabalho, alegando não se sentirem donos das terras e, além disso, por serem apenas 20 há, o que significa para eles não ter terra quando os filhos estiverem grandes e precisarem trabalhar. Portanto, a venda de força de trabalho passa a ser uma alternativa para a mobilidade social.

$\mathrm{O}$ fato de registrar que pequenas porções de terras são problemas para as famílias na Amazônia não significa falta de credibilidade no formato de ocupação PDS, pelo contrário, faz-se aqui uma constatação que remete a outro fenômeno percebido, a formação e qualificação dos moradores dessas áreas. Caso fossem mais bem conscientizados do aproveitamento dos recursos naturais sem terem que desmatar e continuar ampliando suas áreas de roçados, maiores seriam as possibilidades e alternativas para as famílias residentes desse formato de ocupação.

Partindo desse fato, o problema recai na contradição existente entre as trajetórias, a cultura e os hábitos dos produtores migrantes da região com o formato implantado. Mesmo assim, acredita-se que trabalho como atualmente tem sido feito, fre- quentes melhorias para localidade e divisão igualitária entre as famílias dos retornos financeiros da venda organizada de madeira a partir do plano de manejo e acordos com empresas responsáveis pela exportação, evidentemente, tornam viável a continuidade dos formatos de PDS.

No caso dos assentados, famílias de Senador José Porfírio, o problema está nas distâncias que os produtores familiares precisam percorrer em estradas precárias para comercializar seus produtos, desistindo muitas vezes de fazer o percurso, negociam com atravessadores, quase sempre um fazendeiro em condições melhores, donos de propriedades de médio ou grande porte e também proprietários do caminho responsável pelo transporte de pessoas e produtos da localidade ao centro comercial de Altamira. Registra-se que o número de produtores vendendo suas mercadorias pessoalmente na feira dos produtores é baixo. A maioria que hoje assume a venda na feira são os atravessadores, ratificando o fato de baixa participação do produtor na formação do preço final do produto.

\section{Conclusões}

As famílias podem se viabilizar enquanto sujeitos do desenvolvimento territorial, mantendo suas lógicas. No entanto, faz-se necessário a atuação por parte dos governantes, reparando os equívocos e possibilitando condições de vida digna e com qualidade aos produtores e seus familiares, contrastando com as ações, até hoje, realizadas pelos governos de favorecimento a pequenos grupos detentores de capital ao invés de subsidiar e estimular a produção que certamente se faz presente no agrário com menos danos ao meio ambiente e maior geração de emprego e renda.

Ficou evidenciado que não ocorreu a eliminação da produção agropecuária familiar; pelo contrário, essa, ao responder aos estímulos, procurou ocupar os espaços para se fazer sujeito do território em construção.

Verificou-se que a transformação, mediante a interferência do capital, na tentativa de homoge- 
neizar as relações, induziram os produtores familiares cada vez mais as dinâmicas capitalistas, consequentemente moldando as diferentes racionalidades na condução dos seus sistemas de produção. Nesse sentido, ratifica-se a hipótese de que há diferentes formas de produção e estratégias de reprodução das famílias, criando mecanismos diversos e recorrendo às inúmeras alternativas para se viabilizarem no espaço agrário.

O estudo apontou um contraponto em relação à afirmação feita por Lênin (1980, p. 45) que "a tendência fundamental e principal do capitalismo consiste na eliminação da pequena produção pela grande". A eliminação seria num longo processo de ruína, não como uma expropriação imediata, com uso excessivo do trabalho, com o endividamento e sem progresso técnico, portanto, traduzido na deterioração do pequeno produtor até o seu fim. Mas, ao invés de eliminá-los do espaço agrário, notou-se a valorização das desigualdades e adversidades como meios de se obter lucros facilitados e, consequentemente, a acumulação do capital.

Constatou-se, ainda, que, apesar de a produção agropecuária familiar sofrer historicamente a interferência do capital, essa não abandonou os traços que garantem a produção racionada no uso dos recursos naturais e na produção gerada e que essa necessita de incentivos e acompanhamentos para se estabilizarem na terra; precisa ter minimente suas necessidades básicas atendidas; participar de formação/capacitação para o manejo adequado dos recursos naturais; ser estimulada à organização social e precisa de áreas no mínimo na proporção dos módulos rurais - os minifúndios dificultam a percepção do pertencimento do lugar.

A configuração de respeito e compreensão da produção agropecuária familiar como alternativa para o desenvolvimento deve ter inicialmente o entendimento que o sistema capitalista está no sentido contrário de uma agricultura racional ou que essa é incompatível com as determinações e estratégias do sistema propriamente capitalista. Portanto, a condição vivenciada pelos produtores durante a pesquisa pode ser alterada no sentido de serem alternativas para o desenvolvimento com a proposição de romper com o modelo imposto historicamente. Para isso, é necessário que sejam propostas ações pautadas nas estruturas, condições e culturas locais.

Pokorny et al. (2010, p. 150-159), em estudos sobre a Amazônia, descrevem três propostas pautadas na produção familiar. Em concordância, são assumidas as propostas como alternativa para o desenvolvimento da Amazônia. São elas: a) em lugar de estabelecer os projetos para produtores locais, é necessário acompanhar os produtores em seus próprios projetos; b) fortalecimento das capacidades locais e valorização da cultural local e c) não adaptar os produtores familiares aos modelos de desenvolvimento determinados por atores externos, mas adaptar o contexto legal-institucional ao modelo socioprodutivo da produção familiar (POKORNY et al., 2010, p. 150-159).

Por fim, é possível o desenvolvimento na Amazônia incentivar as dinâmicas locais de produção, as formas familiares de produzirem que não degradam os recursos naturais em quantidades similares aos grandes empreendimentos e geram emprego e renda para parte expressiva da população agrária. Isso significa permitir que produtores familiares sejam sujeitos do desenvolvimento com incentivos que considerem suas especificidades dentro da unidade de diversidade que é representada pela produção familiar na região.

\section{Referências bibliográficas}

ABRAMOVAY, R. Paradigmas do capitalismo agrário em questão. 3. ed. São Paulo: EdUsp, 2007. 296 p.

BLUM, R. Agricultura familiar: estudo preliminar da definição, classificação e problemática. In: TEDESCO, J. C. (Org.). Agricultura familiar: realidades e perspectivas. 3. ed. EDIUPF. 2001. 57-106 p.

CHAYANOV, A. V. La Organización de la Unidad Económica Campesina. Buenos Aires, Argentina: Ediciones Nueva Visión, 1974. 342 p.

COSTA, F. de A. Economia camponesa nas fronteiras do capitalismo: teoria e prática nos EUA e na Amazônia 
brasileira. Coleção Economia política da Amazônia. Série II - Fundamentos teórico-metodógicos; v. 1. Belém: NAEA, 2012. 310 p.

FAO/INCRA. Análise diagnóstico de sistemas agrários: guia metodológico. Brasília: FAO/INCRA, 1995. 65 p.

FERNANDES, B. M. e LEAL, G. M. Contribuições teóricas para a pesquisa em geografia agrária. In: IV Encontro Nacional de Pós-graduação em Geografia. São Paulo: ANPEGE / USP, 2002. 39 p.

GARCIA JR., A. R. e HEREDIA, B. A. Campesinato, família e diversidade de explorações agrícolas no Brasil. In: GODOI, E. P. de., MENEZES, M. A. de e MARIN, R. A. (Orgs.). Diversidade do campesinato: expressões e categorias, v.2: estratégias de reprodução. São Paulo: Editora UNESP; Brasília, DF: Núcleo de Estudos Agrários e Desenvolvimento Rural, 2009. 331 p.

HERRERA, J. A. Desenvolvimento capitalista e realidade da produção agropecuária familiar na Amazônia Paraense. Tese (Doutorado). UNICAMP. Campinas, SP. 2012. 335 p.

IBGE. Instituto Brasileiro de Geografia e Estatística. Censo demográfico de 2010. Disponível em: < http:// www.ibge.gov.br/> . Acesso em: 14 jan. 2010.

KAUTSKY, K. A questão agrária. Trad. de C. Iperoig. Rio de Janeiro: Editora Laemmert S. A., 1968. 325 p.

LAMARCHE, H. A agricultura familiar: comparação internacional - uma realidade multiforme. Vol. 1. Coleção Repertórios. Campinas: Ed. UNICAMP, 1993. 336 p.

LÊNIN, V. I. O capitalismo e agricultura nos Estados Unidos: novos dados sobre as leis de desenvolvimento do capitalismo na agricultura. Apresentação de Wladimir Pomar. São Paulo: Editora Debates, 1980. 63 p. (Coleção alicerces)

LIMA, A. P. de, BASSO, N., NEUMANN, P. S., SANTOS, A. C. dos e MÜLLER, A. G. Administração da unidade de produção familiar: modalidades de trabalho com agricultores. 3. ed. Ijuí: Editora UNIJUI, 2005. 224 p.
NEVES, D. P. Agricultura familiar: quantos ancoradouros! 2006. Acesso em: <http://www2.prudente.unesp.br/ dgeo/nera/Bernardo2006_bibliografia/Agricultura_ Familiar.pdf $>$.

O Econômico e o Familiar: interdependências, potencialidades e constragimentos. In: MOTA, D. M. da, TAVARES, E. D., GUEDES, V. G. e NOGUEIRA, F. Agricultura Familiar: desafios para a sustentabilidade. Aracajú: Embrapa - CPATC: SDRMA, 1998.

NORONHA VIANA, A. B. Estatística Aplicada à Administração: análise do uso em pesquisas na área e construção de ambiente virtual de ensinoaprendizagem. Tese de Livre docência. Ribeirão Preto: FEAC/USP. 2005. 218 p.

PLOEG, J. D. V. D. O modo de produção camponês revisitado. In: SCHNEIDER, S. (Org.). A diversidade da agricultura familiar. Porto Alegre: Editora da UFRGS, 2006. 13-54 p.

PORKONY, B., GODAR, J., HOCH, L., JOHNSON, J., de KONING, J., MEDINA, G., STEINBRENNER, R., V. e WEIGELT, J. A produção familiar como alternativa de um desenvolvimento sustentável para a Amazônia: lições aprendidas de iniciativas de uso florestal por produtores familiares na Amazônia boliviana, brasileira, equatoriana e peruana. Bogor / Belém: CIFOR. 2010.174 p.

SANTOS, R. A. O. O genius de uma economia: reflexões e propostas sobre o desenvolvimento da Amazônia. In: ARAGON, L. E. e IMBIRIBA, M. de N. O. Populações humanas e desenvolvimento amazônico. Série Cooperação Amazônia. Belém: UFPA. 1989. 351 p.

SCHMITZ, H. e MOTA, D. M. Agricultura familiar: elementos teóricos e empíricos. In: SCHMITZ, H. (Orgs.). Agricultura familiar: extensão rural e pesquisa participativa. São Paulo: Annablume, 2010. 352p.

TEPICHT, J. Marxisme et Agriculture: le paysan polonais. Librairie Armand Colin. Paris. 1973. 251 p. 
Figura 1A. Especificidades da produção agropecuária familiar e da produção agropecuária patronal e tendência quanto ao grau de interferência do capital

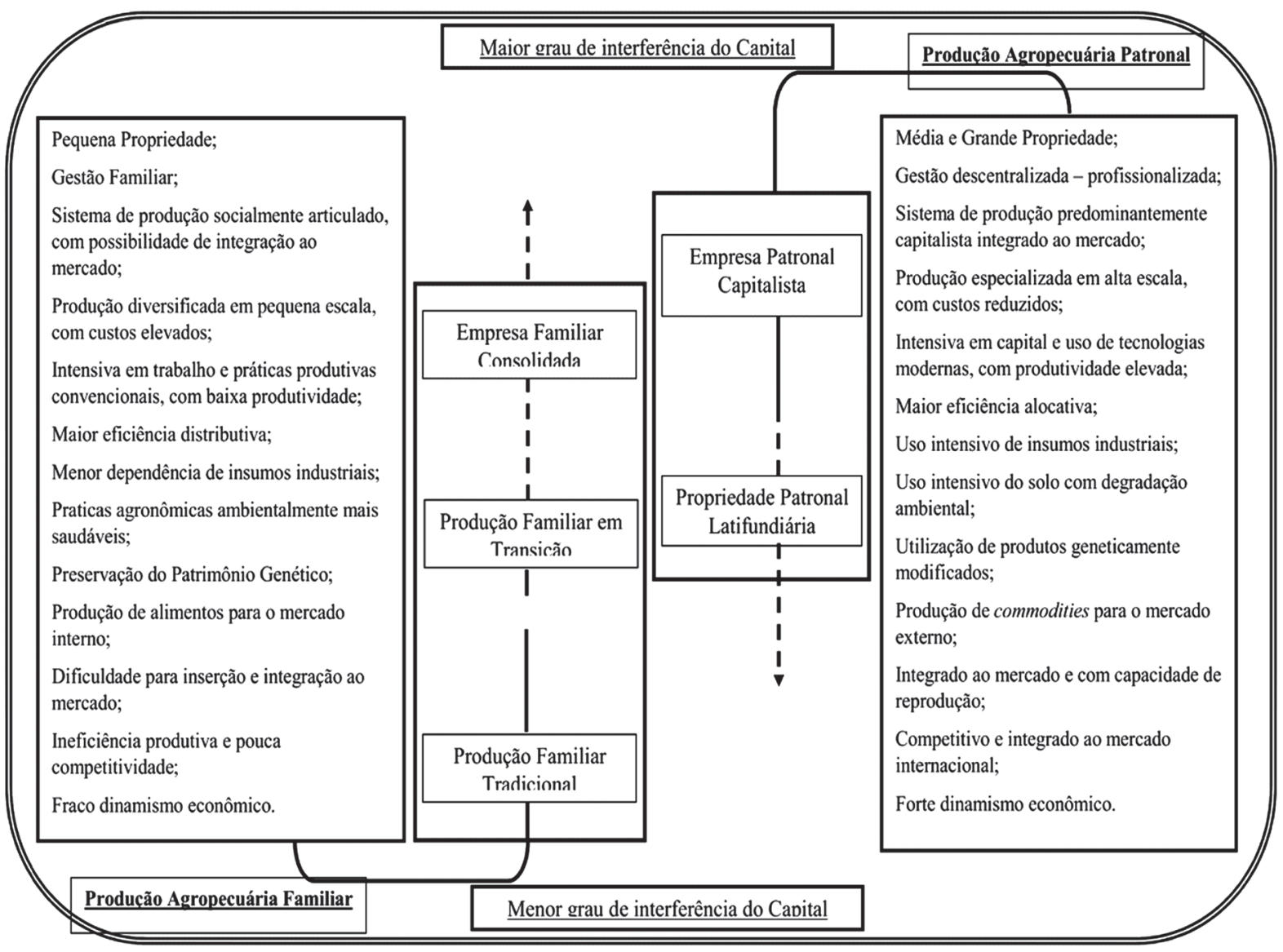

Fonte: Elaboração do autor. 